chỉnh= 3.2, KTC 95\% CI 1.5-6.8).

Tác giả Mousa (2008) [8] nghiên cứu trên 103 trường hợp sản phụ bị BHSS nặng tiên phát (máu mất $\geq 1000 \mathrm{ml}$ hay cần phải truyền máu), trong đó có 22 trường hợp (21\%) điêuu trị nội thất bại sau điều trị hàng thứ 1 . Tác giả không ghi nhận sự khác biệt các yếu tố về tiền căn mẹ (tuổi, BMI, nhóm máu, hút thuốc lá, Rh, chủng tộc), thai kỳ (bệnh TSG, tiểu đường, VMC, đa thai, tuổi thai, thời gian 3 giai đoạn chuyển dạ, sinh giúp, giảm đau sản khoa) ở cả 2 nhóm đáp ứng điều trị và điều trị nội thất bại. Tác giả kết luận các yếu tố nguy cơ không hữu ích trong trong việc tiên đoán khả năng tiếp tục BHSS sau khi thất bại với điều trị ban đầu

\section{KẾT LUẬN}

Các yếu tố tiền căn, lâm sàng, cận lâm sàng liên quan đến can thiệp ngoại khoa băng huyết sau sinh ngã âm đạo nặng.

Nhóm đối tượng nghiên cứu có lượng máu mất trước phẫu thuật/ hậu sản phòng Sinh $\geq$ $1500 \mathrm{ml}$ làm tăng nguy cớ phẫu thuật lên 5,57 lần so với nhóm có máu mất $<1500 \mathrm{ml}$, sự khác biệt này có ý nghĩa thống kê với $p<0,05$.

\section{TÀI LIẸU THAM KHẢO}

1. WHO (2012). WHO recommendations for the prevention and treatment of postpartum haemorrhage. WHO, Avenue Appia 20, CH-1211 Geneva 27 Switzerland: 3-5.

2. WHO (1990). The Prevention and Management of Postpartum Haemorrhage. Report of a Technical Working Group, Geneva, 3-6 July, 1989. Geneva.

3. Trân Văn Vinh (2010). Tình hình băng huyết sau sinh tại Khoa phụ sản BV Đà Nẵng 2005- 2010. Tap chí Phu Sản, 8(2-3): 67- 71.

4. Vằn Thị Kim Huệ, Trương Quang Vinh, Trân Thế Bình, et al. (2010). Điêu trị băng huyết sau sinh. Tap chí Phụ Sản, 8(1): 17-25.

5. Yan JY, Zhou ZMM, Xu X, et al. (2014). Risk factors and surgical interventions associated with primary postpartum haemorrhage unresponsive to first-line therapies.J Obstet Gynaecol, 34(7): 588-92.

6. Grange J, Chatellier M, Chevé MT, et al.(2018). Predictors of failed intrauterine balloon tamponade for persistent postpartum hemorrhage after vaginal delivery. PLoS One., 13(10): e0206663.

7. Revert M, Cottenet J, Raynal P, et al. (2017). Intrauterine balloon tamponade for management of severe postpartum haemorrhage in a perinatal network: a prospective cohort study. BJOG.

8. Mousa HA, Cording V, Alfirevic Z (2008). Risk factors and interventions associated with major primary postpartum hemorrhage unresponsive to first-line conventional therapy. Acta Obstet Gynecol Scand, 87(6): 652-61.

\title{
ĐÁNH GIÁ KẾT QUẢ ĐIỀU TRI GHÉP XƯƠNG GIỮA HAI NHÓM Có VÀ KHÔNG SỬ DỤNG HUYÊT TƯO'NG GIẦU YẾU TỐ TĂNG TRƯởNG
}

\section{TÓM TẮT}

Mục tiêu: Nghiên cứu được thực hiện trên 74 bệnh nhân có khe hở cung hàm một bên tại Bệnh viện Răng Hàm Mặt Trung Uơng Hà Nội và Bệnh viện Đại học Y Hà Nội trong khoảng thời gian từ 12/2014 đến 09/2019, được chia thành 2 nhóm nghiên cứu, nhằm đánh giá kết quả của viêc ghép khung hàm một bên bằng xương mào chậu, có và không sử dụng huyết tương giâuu yếu tố tăng trưởng. Đối tượng và phương pháp: Nghiên cứu được thiết kế theo phương pháp nghiên cứu mô tả với mấu thuận lợi, để đo các kích thước về khả năng tái tạo xương tại khe hở, các yếu tố liên quan xung quanh vị trí khe hở. Kết quả và kết luận: Tỷ lệ tiêu xương được theo dõi sau 12 tháng cho thây chiều dài xương ghép ở nhóm can thiệp tốt hơn so với nhóm đối chứng. Kết quả có ý

${ }^{1}$ Trường Đại học Y Hà Nội

${ }^{2}$ Trường Đai hoc Kinh doanh và Công nghê

Chịu trách nhiệm chính: Tạ Anh Tuấn

Email: taanhtuan@hmu.edu.vn

Ngày nhận bài: 1/11/2020

Ngày phản biên khoa hoc: 14/12/2020

Ngày duyệt bài: 19/12/2020

\section{Tạ Anh Tuấn ${ }^{1}$, Phạm Dương Châu ${ }^{2}$}

nghĩa thống kê trên cỡ mẫu nghiên cứu với $\mathrm{p}=0.045$ (Kiểm định Mann-Whitney).

Tư khóa: Ghép cung hàm, xương mào chậu

\section{SUMMARY}

THE EVALUATION IN BONE GRAFTING IN 2 GROUPS WITH AND WITHOUT USING PLATELET-RICH PLASMA (PRP)

Purpose: The study was conducted on 74 patients with unilateral cleft palate of the National Hospital of Odonto-Stomatology, and Hanoi Medical University Hospital from 12/2014 to 09/2019. was divided into 2 groups, the study is to evaluate the results of alveolar bone graft with ilium bone, with and without using platelet rich plasma (PRP). Subjects and method: The study was designed according to the research method is with convenience sampling to survey the size of bone regeneration capacity at the distance, the related factors around the location of the gap. Results and conclusions: Results showed that the rate of bone resorption in 12 months in group using PRP are lower than group without using PRP, the result was significant, with $p=0,045$, Mann -Whitney test).

Keywords: Alveolar bone graft, iliac bone. 


\section{I. ĐẶT VẤN ĐỀ}

Khe hở môi vòm miêng là môt trong những di tật bẩm sinh phổ biến nhất vùng hàm mặt, tỷ lệ này trên thế giới là $1 / 750-1 / 1000$, tại Việt Nam tỷ lệ này là $1 / 1000$ đến 2/1000 trẻ em sinh ra có di tật [1]. Điều trị toàn diện khe hở môi vòm miệng là quá trình phức tạp, chia làm nhiêu thời kỳ, kéo dài từ khi sinh ra cho đến khi trưởng thành.

Khe hở cung hàm chiếm tỷ lệ 75\% trên tổng số dị tật khe hở môi vòm miệng [2]. Ghép xương ổ răng là một bước quan trọng trong quá trình điều trị toàn diện đối với bệnh nhân khe hở cung hàm. Phương pháp ghép xương ổ răng lân đầu tiên được mô tả bởi Boyne and Sands (1972) [3].Việc ghép xương ổ răng có rất nhiêu ý nghĩa: giúp cho các mâm răng di chuyển và mọc vào khe hở, giúp đảm bảo tính liên tục và ổn định xương hàm trên, giúp đóng lỗ thông mũi miệng, nâng đõ nền mũi, cải thiện tình trạng nha chu, tăng cường hiệu quả nắn chỉnh răng [4].

Hiện nay, có rất nhiều vật liệu dùng để ghép xương như: xương tự thân và xương đông khô khử khoáng. Các loại xương tự thân có thể dùng bao gồm: xương mào chậu, xương sọ, xương sườn, xương chày và xương hàm dưới. Tuy nhiên ghép xương tự thân bằng xương mào chậu luôn là lựa chọn hàng đâu cho kỹ thuật này (chiếm đến $83 \%$ ca ghép) [5].

Phương pháp ghép khe hở cung hàm bằng xương mào chậu ở Việt Nam được dùng khá phổ biến, tuy nhiên lại chưa có một báo cáo tổng kết nào theo dõi và đánh giá kết quả hình thành câu xương trong thời gian dài sau phẫu thuật. Chúng tối tiến hành nghiên cứu đề tài "Nghiên cứu ứng dụng huyết tương giàu yếu tố tăng trưởng trong điều trị ghép xương ổ răng tự thân cho bệnh nhân có khe hở cung hàm".

\section{II. ĐỐI TƯƠNG VÀ PHƯƠNG PHÁP NGHIÊN CỨU}

1. Đối tượng nghiên cứu. Tất cả các bệnh nhân có khe hở cung hàm một bên được chỉ định phẫu thuật và có đây đủ hồ sơ bệnh án.

- Tiêu chuẩn lựa chọn: Bệnh nhân có khe hở cung hàm một bên; Bệnh nhân đã được phẫu thuật hoặc chưa phẫu thuật. Bệnh nhân trên 7 tuổi.

- Tiêu chuẩn loại trừ: Bệnh nhân không đủ sức khỏe để phẫu thuật; Bệnh nhân không đầy đủ hồ sơ bệnh án; Bệnh nhân có khe hở cung hàm hai bên; Bệnh nhân hoặc người giám hộ không đồng ý tham gia nghiên cứu.

\section{Phương pháp nghiên cứu}

- Thiết kế nghiên cứu: Nghiên cứu can thiệp lâm sàng có đối chứng

- Cõ mẫu: Mẫu thuận tiện
- Thời gian và địa điểm nghiên cứu: Những bệnh nhân đủ điều kiện đã tham gia phẫu thuật và hồ sơ từ 12/2014 đến 06/2019 tại các Bệnh viện Răng Hàm Mặt Trung Uơng Hà Nội, Đại học Y Hà Nội.

- Vật liệu và phương tiến hành nghiên cưuu: Hồ sơ Bệnh án, Phiếu nghiên cứu, phim CTCB, bộ dụng cụ phẫu thuật.

- Các biến số nghiên cứu: Độ tuổi, đặc điểm phân loại khe hở, lỗ thông mũi miệng, mức độ hình thành câuu xương, phân loại câuu xương theo thang điểm Kindelan.

Xử lý số liệu: Phim CTCB được đo bằng các chỉ số và xử lý bằng phân mềm SPSS 23.0. Nếu biến phân phối chuẩn, chúng tôi sử dụng $\mathrm{t}$ - test, nếu biến không chuẩn thì sử dụng Mann Whitney test. Để khắc phục sai số, chúng tôi lựa chọn ngấu nhiên 20 phim để đo và tập huấn.

3. Đạo đức trong nghiên cứu: Nghiên cứu chỉ tiến hành trên những đối tượng tự nguyện tham gia nghiên cứu. Được thông qua hội đồng đạo đức Đại học Y Hà Nội

\section{KẾT QUẢ NGHIÊN CỨU}

1. Chîeu dài xương ghép và tỉ lệ tiêu xương sau 3 tháng

\begin{tabular}{|c|c|c|c|}
\hline 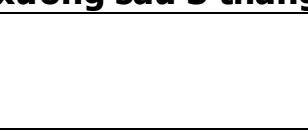 & $\begin{array}{l}\text { Nhóm can } \\
\text { thiệp } \\
M \pm \operatorname{sd}(\%)\end{array}$ & $\begin{array}{c}\text { Nhóm đối } \\
\text { chứng } \\
M \pm s d\end{array}$ & $\begin{array}{c}P \\
\text {-value }\end{array}$ \\
\hline $\begin{array}{l}\text { Chiêu dài xương } \\
\text { ghép } \\
\text { sau } 3 \text { tháng (mm) }\end{array}$ & $\begin{array}{c}14,54 \pm \\
1,28\end{array}$ & $\begin{array}{c}13,72 \pm \\
1,29\end{array}$ & $0.02 *$ \\
\hline $\begin{array}{l}\text { Tỉ lệ chênh của sự } \\
\text { tiêu xương ghép so } \\
\text { với chiều dài trung } \\
\text { bình khe hở(\%) }\end{array}$ & $\begin{array}{c}15,85 \pm \\
7,01\end{array}$ & $\begin{array}{c}11,08 \pm \\
7,11\end{array}$ & $<0,01 *$ \\
\hline
\end{tabular}

Sau 3 tháng, chiêu dài xương ghép của nhóm can thiệp tốt hơn so với nhóm đối chứng $(14,54$ $\pm 1,28$ so với $13,72 \pm 1,29)$. Sự khác biệt có ý nghiã thống kê trên cỡ mẫu nghiên cứu với $p=$ 0,02 (kiểm định Mann - Whitney test). Tỉ lệ chênh của sự tiêu xương ghép so với chiêuu dài khe hở trung bình của nhóm can thiệp cũng lớn hơn so với nhóm đối chứng. Sự khác biệt có ý nghĩa thống kê trên cỡ mẫu nghiên cứu với $\mathrm{p}<$ 0,01 (kiểm định Mann - Whitney test)

2. Chiêu dài xương ghép và tỉ lệ tiêu xương sau 6 tháng

\begin{tabular}{|c|c|c|c|}
\hline & $\begin{array}{c}\text { Nhóm can } \\
\text { thiệp } \\
\mathrm{M} \pm \mathrm{sd}(\%)\end{array}$ & $\begin{array}{c}\text { Nhóm đối } \\
\text { chứng } \\
\mathrm{M} \pm \mathrm{sd}\end{array}$ & $\begin{array}{c}\mathrm{p} \text { - } \\
\text { value }\end{array}$ \\
\hline $\begin{array}{c}\text { Chiều dài } \\
\text { xương ghép } \\
\text { sau 6 tháng } \\
(\mathrm{mm})\end{array}$ & $\begin{array}{c}12,01 \pm \\
1,17\end{array}$ & $\begin{array}{c}11,62 \pm \\
1,1\end{array}$ & $0,1^{*}$ \\
\hline
\end{tabular}




\begin{tabular}{|c|c|c|c|}
\hline $\begin{array}{c}\text { Tỉ lệ tiêu xương } \\
\text { ghép tháng } \\
3-6(\%)\end{array}$ & $17,26 \pm$ & $18,29 \pm$ & $0,93^{*}$ \\
\hline
\end{tabular}

Sau 6 tháng cho thấy chiều dài xương ghép và tỉ lệ tiêu xương từ tháng thứ 4 đến tháng thứ 6. Chiều dài xương ghép ở nhóm can thiệp dài hơn ở nhóm đối chứng, tuy nhiên sự khác biệt không có ý nghĩa thống kê trên cõ̃ mẫu nghiên cứu với $\mathrm{p}=0,1$ (kiểm định Mann - Whitney). Tỉ lệ tiêu xương tữ tháng thứ 4 đến tháng thứ 6 ở 2 nhóm nghiên cứu là như nhau với $\mathrm{p}=0.93$ (kiểm định Mann - Whitney)

3. Chiêu dài xương ghép và tỉ lệ tiêu xương sau 12 tháng

\begin{tabular}{|c|c|c|c|}
\hline & $\begin{array}{c}\text { Nhóm can } \\
\text { thiệp } \\
\text { M } \pm \text { sd }\end{array}$ & $\begin{array}{c}\text { Nhóm đối } \\
\text { chứng } \\
\mathbf{M} \pm \text { sd }\end{array}$ & p-value \\
\hline $\begin{array}{c}\text { Chiều dài } \\
\text { xương ghép } \\
\text { sau 12 tháng } \\
\text { (mm) }\end{array}$ & $\begin{array}{c}9,44 \pm \\
0,92\end{array}$ & $8,29 \pm 2,22$ & $<\mathbf{0 , 0 1 *}$ \\
\hline $\begin{array}{c}\text { Tỉ lệ tiêu } \\
\text { xương ghép } \\
\text { tháng 12-6 } \\
\text { (\%) }\end{array}$ & $\begin{array}{c}20,87 \\
\pm 8,63\end{array}$ & $\begin{array}{c}24,07 \pm \\
8,37\end{array}$ & $\mathbf{0 , 1 * *}$ \\
\hline $\begin{array}{c}\text { Tî lệ tiêu } \\
\text { xương ghép } \\
\text { háng 12-3(\%) }\end{array}$ & $\begin{array}{c}35,03 \pm \\
4,93\end{array}$ & $35,99 \pm 4,9$ & $\mathbf{0 . 3 9 *}$ \\
\hline
\end{tabular}

Sau 12 tháng theo dõi trên đối tượng cứu cho thấy. Tỉ lệ tiêu xương từ tháng thứ 4 đến tháng thứ 12 ở 2 nhóm là như nhau $\left(\mathrm{p}_{12-3}=0.39\right.$ và $\left.p_{12-6}=0,1\right)$. Tuy nhiên sau 12 tháng theo dõi, chiều dài xương ghép ở nhóm can thiệp tốt hơn so với nhóm đối chứng. Kết quả có ý nghĩa thống kê trên cõ̃ mẫu nghiên cứu với $\mathrm{p}<0,01$ (kiểm định Mann - Whitney)

\section{BÀN LUÂ̂N}

Trong nghiên cứu này khe hở cung hàm đo được trước phẫu thuật của hai nhóm nghiên cứu theo thứ tự: nhóm can thiệp có chiều cao trung bình là 12,59mm, trong khi đó nhóm đối chứng có kết quả với chiều cao: $12,39 \mathrm{~mm}$ số liệu này cho thây chiều cao cung hàm ở nhóm 1 cao hơn không đáng kể so với nhóm 2 (gần như không có sự khác biệt). Sự không khác biệt này sẽ cho phép chúng tôi nghiên cứu mức độ tiêu xương ghép sau phẫu thuật có kết quả tin cậy. Caroline Dissaux (2016) khi nghiên cứu kết quả ghép xương khe hở cung hàm ở lứa tuổi từ 5 đến 10 cho thây chiều cao trung bình xương cung hàm cần ghép là $11,0 \pm 1,5$ và độ rộng là $7,1 \pm 1,3$ khác biệt về chỉ số này so với nghiên cứu của chúng tôi là không nhiều, sự khác biệt chủ yếu là do lứa tuổi khác nhau. Cùng với sự phát triển của $C T$ - Cone beam và các phần mềm $C A D$ CAM các nghiên cứu về khe hở cung hàm trong thời gian gần đây đều hướng tới việc tính thể tích vùng khe hở [6]. Vậy câu hỏi đặt ra là chỉ theo dõi chiều cao xương ghép vùng khe hở có đánh giá được mức độ tiêu xương ghép hay không? Dựa theo cách tính điểm của Bergland và Kindelan dưới đây [7]

Bảng 1: Bảng tính điểm chiều cao xương ghép của Bergland

\begin{tabular}{|c|c|}
\hline $\begin{array}{c}\text { Thanng } \\
\text { điểm }\end{array}$ & $\begin{array}{c}\text { Chiều cao xương ghép } \\
\text { I }\end{array}$ \\
\hline Được gần như chiều cao cần bù \\
\hline II & Chỉ được $3 / 4$ chiều cao cần bù \\
\hline III & Dưới $3 / 4$ chiều cao cần bù \\
\hline IV & Chỉ còn cầu xương \\
\hline
\end{tabular}

Bảng 2: Bảng tính điểm chiều cao xương ghép của Kindelan

\begin{tabular}{|c|c|}
\hline Thang điếm & Chiêu cao xương ghép \\
\hline 1 & $>75 \%$ \\
\hline 2 & $50 \%-75 \%$ \\
\hline 3 & $<50 \%$ \\
\hline 4 & Không còn xương \\
\hline
\end{tabular}

Chúng tôi cho rằng việc ghi nhận chiều cao xương ghép vẫn còn nguyên giá trị để đánh giá mức độ tiêu xương ghép trong nghiên cứu của minh.

Kết quả sau 1 tuân. Tỉ lệ lành thương trên lâm sàng tại thời điểm 7 ngày sau phấu thuật của các đối tượng nghiên cứu. Trong đó, tỉ lệ lành thương tốt ở nhóm can thiệp và nhóm đối chứng lần lượt là $89,74 \%$ và $71,43 \%$. Tỉ lệ lành thương xâu ở nhóm can thiệp và nhóm đối chứng lần lượt là $10,26 \%$ và $28,57 \%$. Như vậy, ở nhóm can thiệp có sự lành thương trên lâm sàng tốt hơn nhóm đối chứng tại thời điểm 7 ngày sau phẫu thuật; sự khác biệt có ý nghĩa thống kê trên cõ̃ mẫu nghiên cứu với $p=0,045$ (kiểm định bằng test $X^{2}$ ). Nhưng nghiên cứu này thực hiện tại 2 cơ sở phẫu thuật, cùng một nhóm phẩu thuật viên, với kết quả có sự khác biệt lên tới $18 \%$ đã thể hiện rõ hiệu quả của sự có mặt của PRP trong vật liệu ghép - một trong nhân tố quan trọng tham gia vào hoạt động chống viêm của quá trình lành thương. Theo Mooren khi có măat của PRP trong thành phần xương ghép, ở giai đoạn sớm 1 tuần sau phẫu thuật thì chưa có sự sinh xương tại vị trí tiếp giáp giữa xương ghép và vùng nhận, lúc này chỉ có lượng nhỏ tổ chức sợi quanh vùng ghép và chỉ có hiện tượng tiêu viêm tại chính xương ghép và tiếp giáp giữa xương ghép và vùng nhận [8]. Chandan Gupta và cộng sự năm 2013 khi nghiên cứu ghép xương khe hở cung hàm trên hai nhóm nghiên 
cứu: sử dụng PRP và không có PRP kết hợp với xương tự thân cho thấy: đến $90 \%$ bệnh nhân có sử dụng PRP lành thương sớm so với $70 \%$ ở nhóm không có PRP. Chúng tôi hoàn toàn đồng ý với Mooren [8] giai đoạn một tuần sau ghép xương kết quả đáng lưu ý nhất đó là sự tham gia tiêu viêm của PRP tại vùng ghép làm cho quá trình sinh xương và lành thương tiếp theo diễn ra nhanh hơn và hiêuu quả hơn.

Kết quả sau 3 tháng. Cũng theo Mooren ở tuần lễ thứ 2 bắt đầu xuất hiện nhiều tế bào viêm, cũng như dấu hiệu tiêu xương vừa phải ở chính xương ghép. Kèm với nó là sự có mặt của tế bào hủy xương. Một vài khoảng trống trong mảnh xương ghép được quan sát thấy. Sự hình thành xương mới bắt đầu được quan sát thây tại tiếp giáp giữa xương ghép và xương nhận, tuy nhiên không thấy nhiều tế bào xương.

Vào tuần thứ 6 sau ghép xương: không còn dấu hiệu viêm tại vùng ghép. Cũng còn ít dấu hiệu của xương ghép được nhận dạng. Khối lượng xương ghép tại thời điểm này giảm đi rất nhiều so với tuần lễ đầu tiên sau ghép xương.

Vào tuần thứ 12 sau ghép xương: không còn dấu hiệu viêm tại vùng ghép. Chỉ còn thấy rất ít dấu hiệu của xương ghép ban đầu, nhưng không thể xác định được ranh giới giữa xương ghép và xương mới. Những lát cắt qua vùng ghép không thây những hốc rồng. Việc tiêu xương ghép giai đoạn từ tuần thứ 6 tới tuần thứ 12 ít hơn nhiêu so với giai đoạn từ tuần thứ 2 đến tuần thứ 6 [8].

Theo Sameh khi bàn về vật liệu cho ghép xương khe hở cung hàm có đề cập tới PRP, một vật liệu sinh học tự thân, mang theo nhiều tác nhân tăng trưởng, có tác động rất sớm tới quá trình lành thương tại vùng ghép xương, đó là chống viêm, tái tạo mao mạch, đến giai đoạn tiếp theo là kích thích sinh xương mới và hạn chế tiêu xương.

Trong nghiên cứu của chúng tôi thì thây chiều dài xương ghép và tỉ lệ chênh của xương ghép sau 3 tháng. chiều dài xương ghép của nhóm can thiệp tốt hơn so với nhóm đối chứng $(14,54$ $\pm 1,28$ so với $13,72 \pm 1,29)$. Sự khác biệt có ý nghiã thống kê trên cõ̃ mẫu nghiên cứu với $p=$ 0,02 (kiểm định Mann - Whitney test). Tỉ lệ chênh của sự tiêu xương ghép so với chiều dài khe hở trung bình của nhóm can thiệp cũng lớn hơn so với nhóm đối chứng. Sự khác biệt có ý nghĩa thống kê trên cõ̃ mẫu nghiên cứu với $\mathrm{p}<$ 0,01 (kiểm định Mann - Whitney test)

Kết quả sau 6 tháng. Việc sinh xương và hình thành xương mới trong quá trình lành thương sau ghép xương hoàn tất ở tháng thứ tư sau ghép. Từ lúc này chỉ còn hiện tượng tiêu xương ghép, sự tiêu xương này cũ̃ng giảm dần theo thời gian. Nghiên cứu của chúng tôi cũng phản ánh rõ điều này. Chiều dài xương ghép sau 6 tháng ở nhóm can thiệp là $12,01 \mathrm{~mm}$ và nhóm đối chứng $11,62 \mathrm{~mm}$. Và tỉ lệ tiêu xương ghép từ tháng 3 đến tháng thứ 6 là 17,26\% ở nhóm can thiệp và $18,29 \%$ ở nhóm đối chứng là như nhau với $p=0.93$ (kiểm định Mann-Whitney). Kết quả này cho thấy mức độ tiêu xương ghép đã giảm đi rất nhiều trong giai đoạn này. Sự khác biệt về mức độ tiêu xương giữa hai nhóm là không đáng kể.

Kết quả sau 12 tháng. Thời điểm này ở nhóm can thiệp, chiều dài trung bình xương ghép là 9,44mm và nhóm đối chứng là $8,29 \mathrm{~mm}$. Giai đoạn này là giai đoạn ổn định không còn hoạt động tái tạo nào tại vùng xương ghép, nhưng kết quả nghiên cứu cho thấy sự tiêu xương ghép vẫn diễn ra, với mức độ đáng kể, nhưng vẫn có sự khác biệt về tiêu xương giữa 2 nhóm nghiên cứu. Sau 12 tháng theo dõi, chiều dài xương ghép ở nhóm can thiệp tốt hơn so với nhóm đối chứng. Kết quả có ý nghĩa thống kê trên cõ̃ mẫu nghiên cứu với $\mathrm{p}<0,01$ (kiểm định Mann - Whitney)

\section{KẾT LUẬN}

Nghiên cứu 74 đối tượng ghép khe hở cung hàm một bên bằng xương mào chậu, chúng tôi rút ra kết luận sau: Tỷ lệ tiêu xương sau khi ghép xương của khe hở cung hàm thì phụ thuộc nhiều yếu tố, trong nghiên cứu của chúng tồi, việc ghép xương cung hàm có sử dụng thêm huyết tương giâu tiểu câu có thể làm giảm đi tỉ lệ tiêu xương sau ghép xương. Đây là một trong những căn cứ để người phẫu thuật viên có thể lựa chọn trong điều trị ghép xương khe hở cung hàm cho bệnh nhân.

\section{TÀI LIỆU THAM KHẢO}

1. Pham Dương Châu (2012) "Đánh giá kết quả ghép xương ô răng ở bệnh nhân sau mổ tạo hình khe hở môi vòm miệng," Tạp chí Y học thực hành.

2. E. S. Tichvy Tammama, Journal of Dentomaxillofacial Science, vol. 37, (J Dentomaxillofac Sci) , April 2017, pp. P-ISSN.25030817, E-ISSN.2503- 0825 .

3. S. N. R. Boyne PJ (1972), "Secondary bone grafting of residual alveolar and palatal clefts," Journal of Oral Surgery 30, MĐ.

4. S. G. A. F. Bergland O (1986) "Elimination of the residualalveolar cleft by secondary bone grafting and subsequent orthodontic treatment," Cleft Palate J..

5. J. A. L. J. Ananth S. M (2005). "Evaluation of Alveolar Bone Grafting: A Survey of ACPA Teams," The Cleft Palate-Craniofacial Journal, 42(1).

6. C.P. Kasaven(2016), "Accuracy of both virtual 
and printed 3-dimensional models for volumetric measurement of alveolar clefts before grafting with alveolar bone compared with a validated algorithm: a preliminary investigation", British Journal of Oral and Maxillofacial Surgery, Vol 55, p31 - 36.

7. Hynes P. J., Earley M. J. (2003), "Assessment of secondary alveolar bone graftingusing a modification of the Bergland grading system", The British Association of Plastic Surgeons, Vol 562003, p630 - 636 .

8. R. E. C. M. Mooren, (2007), "The effect of platelet - rich plasma on early and late bone healing: an experimental study in goats", Int. J. Oral Maxillofac. Surg. 2007, Vol36, p626-631.

\section{KHẢO SÁT TÁC ĐộNG CỦA TENOFOVIR DISOPROXIL FUMARATE LÊN CHỨC NĂNG THẬN Ở BỆNH NHÂN VIÊM GAN VI RÚT B MẠN}

\section{TÓM TẮT}

Mục tiêu: Khảo sát tác động của tenofovir disoproxil fumarate (TDF) lên chức năng thận ở bệnh nhân viêm gan vi rút $B$ mạn. Đối tượng và phướng pháp: Nghiên cứu cắt ngang mô tả tiến hành trên 60 bệnh nhân viêm gan $B$ mạn điều trị ngoại trú với TDF tại Bệnh viện Đại Học Y Dược TP HCM từ tháng 05/2017 đến tháng 10/2020. Kết quả: Tuổi trung bình trong nghiên cứu là $42,10 \pm 13,30$; Tỷ lệ nam giới 39/60 (65,0\%). Mức creatinine trung bình đã̃ tăng đáng kể ở tuần thứ 24 và $48(p<0,01)$. Tương tự, độ lọc cầu thận ước tính (estimated Glomerular Filtration Rate - eGFR) giảm có ý nghĩa ở tuần thứ 24 và 48 ( $\mathrm{p}$ $<0,05)$. Kết luận: Kết quả nghiên cứu cho thây chức năng thân giảm so với ban đầu ở bênh nhân viêm gan vi rút $\mathrm{B}$ mạn điều trị TDF, cho thấy chức năng thận cần được theo dõi thường xuyên ở những bệnh nhẩn đang điều trị với TDF. mạn.

Tư khóa: TDF, chức năng thận, viêm gan vi rút B

\section{SUMMARY}

\section{EFFECT OF TENOFOVIR DISOPROXIL} FUMARATE ON RENAL FUNCTION IN PATIENTS WITH CHRONIC HEPATITIS B

Objective: To evaluate the effect of tenofovir disoproxil fumarate (TDF) on renal function in patients with chronic hepatitis B. Methods: A cross-sectional study was conducted on 60 patients with chronic hepatitis B at University Medical Center HCMC from May 2017 to October 2020. Results: The mean age of patients was $42.10 \pm 13.30 ; 39 / 60(65 \%)$ of patients were male. The mean creatinine level significantly increased at $24^{\text {th }}$ and $48^{\text {th }}$ week of treatment ( $p<0.01)$, while eGFR level significantly decreased at $24^{\text {th }}$ and $48^{\text {th }}$ week $(p<0.05)$. Conclusion: Renal function was decreased relative to baseline in chronic hepatitis $B$ patients receiving TDF

${ }^{1}$ Đại học Y Dược Thành phố Hồ Chí Minh ²Bệnh viện Chợ Rẫy, Thành phố Hồ Chí Minh

Chiu trách nhiệm chính: Võ Duy Thông

Email: duythong@ump.edu.vn

Ngày nhận bài: 26.10.2020

Ngày phản biên khoa họ: 27.11.2020

Ngày duyệt bài: 2.12.2020

\section{Võ Duy Thông ${ }^{1,2}$, Võ Ngọc Diễm ${ }^{1}$}

therapy, which indicates that the renal function should be monitored regularly in patients undergoing treatment with TDF.

Key words: TDF, renal function, chronic hepatitis B.

\section{I. ĐĂT VẤN ĐỀ}

Nhiễm viêm gan vi rút $B$ (Hepatitis $B$ virus $\mathrm{HBV}$ ) là một vấn đề sức khỏe toàn cầu. Trên toàn thế giới, ước tính có khoảng 240 triêu người bị nhiễm viêm gan vi rút $B$ mạn, đặc biêt ở các nước có thu nhập thấp và trung bình. Các biến chứng chính của viêm gan vi rút $\mathrm{B}$ mạn là xơ gan và ung thư biểu mô tế bào gan (HCC). Khoảng $20 \%$ đến $30 \%$ trong số những người bị viêm gan vi rút $\mathrm{B}$ man sẽ phát triển các biến chứng này, và ước tính khoảng 650000 người sẽ tử vòng hàng năm [1]. Những tiến bô trong điều trị kháng ví rút đã cải thiện đáng kể tiên lượng nhiễm HBV. Tenofovir disoproxil fumarate (TDF) là một tiền chất sinh khả dụng của tenofovir, là một nucleotide manh ức chế quá trình phiên mã ngược HBV [1]. TDF được thải trừ bởi quá trình thanh thải ở thận, phần lớn qua lọc cầu thận; $20 \%-30 \%$ được vận chuyển tích cực vào tế bào ống lượn gần. Độc tính trên thận do TDF chủ yếu dẫn đến tổn thương ống thận gần [2]. Vì vậy, chúng tôi thực hiện đề tài này nhằm khảo sát tác động của TDF lển chức năng thận ở bệnh nhân viêm gan vi rút $B$ mạn.

\section{II. ĐỐI TƯỢNG VÀ PHƯƠNG PHÁP NGHIÊN CỨU}

Thiết kế nghiên cứu: Nghiên cứu cắt ngang mô tả trên hồ sơ bệnh án của bệnh nhân viêm gan vi rút $B$ mạn điều trị TDF.

\section{Đối tượng nghiên cứu}

Tiêu chuẩn chơn bệnh nhân nghiên cứu: 60 bệnh nhân được chẩn đoán xác định viêm gan vì rút $B$ mạn điều trị ngoại trú với TDF tại Bệnh viện Đại Học Y Dược TP. Hồ Chí Minh từ 05/2017 đển $10 / 2020$

- Tiêu chuấn loại trứ: Đồng nhiễm viêm gan vi rút $\mathrm{C}, \mathrm{HIV}$; Có bệnh gan cấp tính do HAV, 